\title{
Influence of Chromium Concentration on Corrosion Resistance of Surface Layers of Stainless Steel
}

\author{
Evdokiya Bushueva $^{1 *}$, YevgenyTurlo ${ }^{2}$, and Galina Khamgushkeeva ${ }^{1}$ \\ ${ }^{1}$ Novosibirsk State Technical University, Department of Material Science in Mechanical Engineering, \\ 20 K. Marx Pr., 630073 Novosibirsk, Russian Federation \\ ${ }^{2}$ Novosibirsk State Technical University, Department of Chemistry and Chemical Technologies, $20 \mathrm{~K}$. \\ Marx Pr., 630073 Novosibirsk, Russian Federation
}

\begin{abstract}
Phase transformations occurring during the non-vacuum electron-beam surfacing using a mixture of amorphous boron and chromium powder (from 5 to $30 \mathrm{wt} \%$ ) as well as the effect of the resulting structure on the corrosion resistance of the surface layers of chromiumnickel austenitic steel have been investigated. It has been found that when processing a powder mixture with a minimum chromium content (5 and 10 wt\%), layers with a dense arrangement of borides are formed. Further increase in chromium concentration (20 and $30 \mathrm{wt} \%)$ leads to the formation of solid solutions in the modified layer. It has been shown that an increase in the concentration of chromium in the surface layer leads to a twofold increase in the corrosion resistance of the 12X18H9T (AISI 302) steel surface.
\end{abstract}

\section{Introduction}

Chromium-nickel steels are highly resistant to corrosion; however, there are conditions under which these steels can undergo local types of corrosion destruction, in particular, inter crystalline corrosion (ICC) [1-4]. ICC tendency develops during operation and as a result of welding heating during the manufacture of equipment. It is important to observe the susceptibility of the material to inter crystalline corrosion and the possibility of avoiding destruction. The use of the electrochemical method, potentiostatic reactivation and determination of steels susceptibility to ICC can solve the problem. The method of anodic etching in inhibited sulfuric acid makes it possible to evaluate the progress of the corrosion process in an accelerated mode. This method is used to control products of chromium-nickel steels; the method is included in Russian standards and is standardized in the ISO system. The method is characterized by high expressiveness and makes it possible to quickly reveal the degree of steels susceptibility to ICC, which is impossible when using

\footnotetext{
${ }^{*}$ Corresponding author: dusias@mail.ru standard chemical methods. Presumably, anodic inhibition will make it possible to evaluate the corrosion resistance of boride layers [5-8]. Thus, the purpose of the experiment is to accelerate the corrosion process and carry it out under more severe conditions in order to reveal differences in the corrosion resistance of layers formed at different surfacing currents
} 
and the use of different types and amounts of wetting components.

In this work, the objects of research were modified layers obtained by cladding of amorphous boron and various wetting components, formed on chromium-nickel steel.

\section{Materials and methods of research}

\subsection{Materials}

Stainless steel plates with dimensions of $100 \times 50 \times 12 \mathrm{~mm}$ were used as substrates. The chemical composition of the steel was as follows: $0.05 \% \mathrm{C}, 0.33 \% \mathrm{Si}, 1.82 \% \mathrm{Mn}$, $0.005 \% \mathrm{~S}, 0.019 \% \mathrm{P}, 17.29 \% \mathrm{Cr}, 8.98 \% \mathrm{Ni}, 0.24 \% \mathrm{Ti}$. A mixture of amorphous boron $40 \mathrm{wt} \%)$, flux $\left(\mathrm{MgF}_{2} 50 \mathrm{wt} \%\right)$ and chromium (as wetting agent; reduced iron TU 6-09-2227$81,5-30 \mathrm{wt} \%$ ) powders was used for cladding. The mass of the powder mixture poured onto $1 \mathrm{~cm}^{2}$ of surface was $0.33 \mathrm{~g}$.

\subsection{Regimes of cladding}

Cladding regimes were chosen based on the investigations and papers made by specialists of the Budker Institute of Nuclear Physics (SB RAS). Accelerating voltage was equal to 1.4 $\mathrm{MeV}$; a beam current of $23 \mathrm{~mA}$ was used. The distance from the outlet window to the working surface is $90 \mathrm{~mm}$. The velocity of sample movement relative to the electron beam was $1 \mathrm{~cm} / \mathrm{s}$.

\subsection{Structure and corrosion research techniques}

Tests to determine corrosion resistance by anodic etching in inhibited sulfuric acid were carried out in accordance with GOST 6032-2003.

The material is subjected to anodic etching in an aqueous solution of inhibited sulfuric acid. This method is applicable for corrosion-resistant steels, for example, 12X18H9, 12X18H9T, 08X18H12T, and others prone to inter crystalline corrosion (ICC). A solution used as an aggressive medium contains $20 \mathrm{~cm} 3$ of urotropine solution and $1000 \mathrm{~cm} 3$ of sulfuric acid solution. Sulfuric acid solution has density of $1.83 \mathrm{~g} / \mathrm{cm} 3$ with a mass fraction of $(60 \pm 0.2) \%$ according to GOST 4204. Urotropin $\left(\mathrm{CH}_{2}\right)_{6} \mathrm{~N}_{4}$ has mass fraction $(0.5 \pm 0.05) \%$ according to GOST 1381. Distilled water corresponds to GOST 6709. Test temperature is $(20 \pm 10){ }^{\circ} \mathrm{C}$. The duration of the tests after turning on the current is $(5 \pm 0.2)$ min. The tests are carried out by anodic etching of the controlled sections of the samples, which are included in the direct current circuit at a current density of $(0.65 \pm 0.01) * 104 \mathrm{~A}$ $/ \mathrm{m}^{2}$. The test sample serves as the anode, the cathode is a massive stainless steel sheet, the cathode dimensions exceed the anode dimensions 3 times.

\section{Results and discussion}

\subsection{Results of optical microscopy}

The results of optical metallography indicated that with the addition of chromium to the powder mixture of 5 and $10 \mathrm{wt} \%$, the structure of the modified layer consisted of chromium borides and doped borides $\mathrm{Cr}_{2} \mathrm{~B}$ and $(\mathrm{Cr}, \mathrm{Fe})_{2} \mathrm{~B}$, respectively. In addition, an increase in the eutectic component with an increase in the amount of chromium additive was recorded in the hardened layer. The eutectic consisted of small borides located in the $\gamma$-Fe matrix. 
These data were also confirmed by X-ray phase analysis. With an increase in the proportion of chromium to 20 and $30 \mathrm{wt} \%$, the strengthening phase (borides) was not fixed. The dendritic structure of the modified layer was observed. The alloyed layer was a solid solution of boron in austenite.

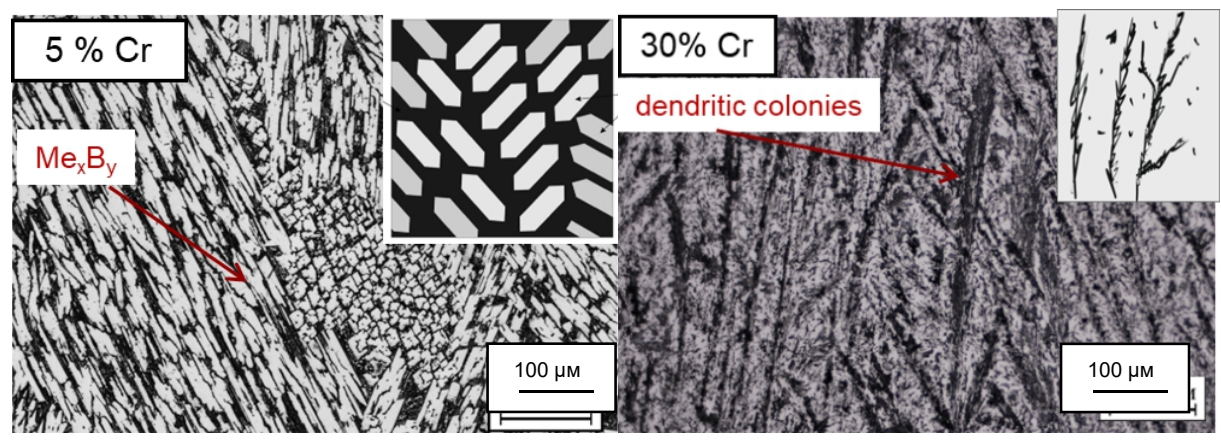

Fig. 1. Microstructure of modified layers of 12X18H9T steel, formed by VELO of boron-containing powders with $\mathrm{Cr}$ a) $5 \mathrm{wt} \%$, b) $30 \mathrm{wt} \%$
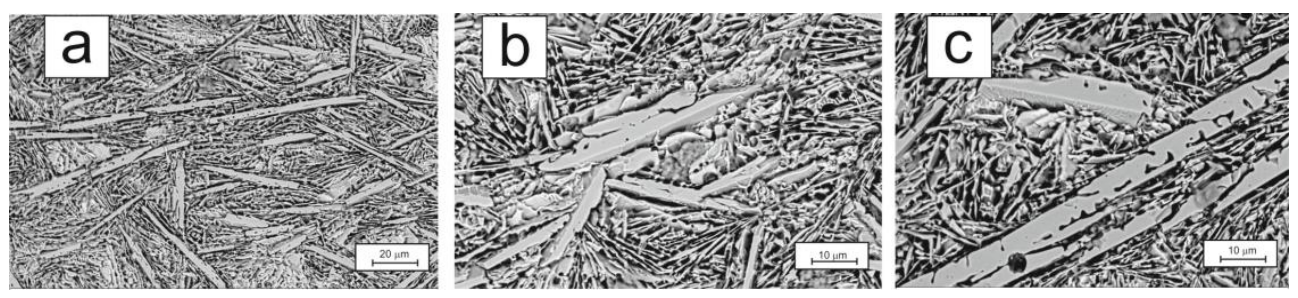

Fig. 2. The surface of the samples obtained by surfacing of amorphous boron, $\mathrm{Cr}$ (10 wt.\%), I = 23 $\mathrm{mA}$ after anodic reactivation in inhibited sulfuric acid, the time equals 5 minutes.

\subsection{Corrosion properties of coatings}

With an increase in the proportion of the wetting chromium component from 5 to $30 \mathrm{wt} \%$ (Fig. 3), an increase in corrosion resistance from 5 to $10 \mathrm{wt} \%$ is observed. This phenomenon is explained by the presence and further increase of chromium borides in the modified layer. Consequently, the proportion of the phase resistant to oxidation increases. Further increase of chromium to 20 and $30 \mathrm{wt} \%$ does not lead to a greater increase in corrosion resistance. This is due to the absence of borides in the modified layer. The amount of boron is insufficient for the formation of borides; dendritic colonies with solid solution hardening are observed in the structure.

As a result, the structure of different zones of the sample transforms into a complex three-phase system "volume of $\gamma$-solid solution | boron depleted zone $\mid$ metal boride". This causes energy heterogeneity of the surface, because of this, microgalvanic couples appear along the boundaries when in contact with the electrolyte. The anode gaps are areas with the minimum potential of microgalvanic couples. These are boron depleted zones. The cathode can be both the phase of the forming chromium boride and the volume of steel which is not subjected to chromium depletion. The kinetics of anodic oxidation is determined by the arising potential difference and the ratio of the surface areas of these phases [5]. 


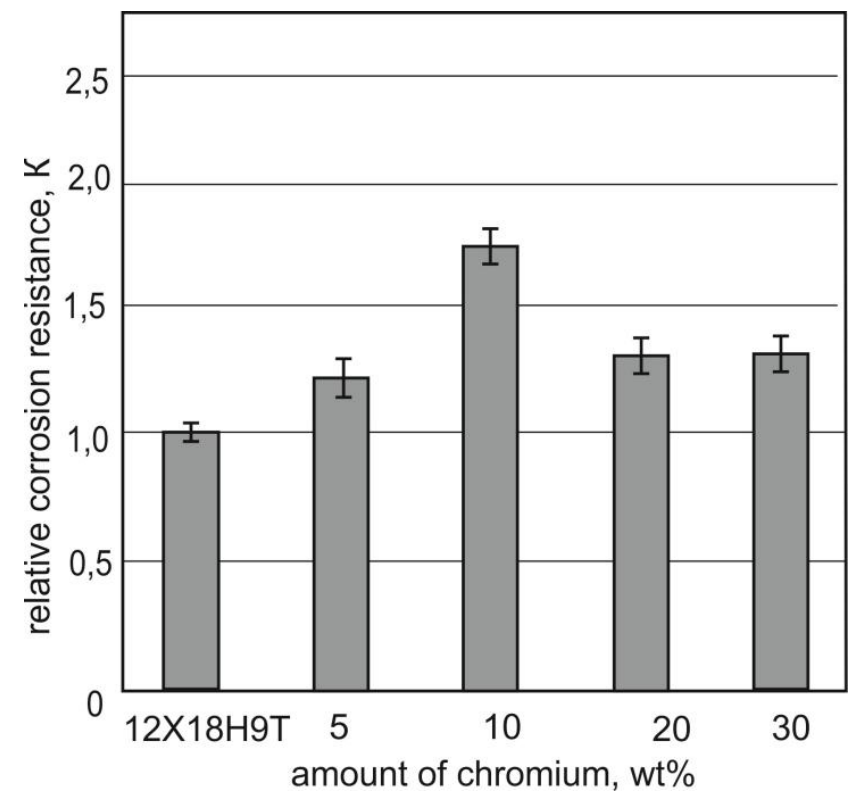

Fig. 3. Dependence of relative corrosion resistance of samples during surfacing of amorphous boron and $\mathrm{Cr}$ on the amount of the wetting component (5-30 wt $\%)$.

These facts indicate that the main oxidizing agents of the obtained materials under these conditions are hydrogen and oxygen cations $[7,8]$.

\section{Conclusion}

Surfacing of a powder mixture of amorphous boron and a wetting component $\mathrm{Cr}(5-30 \mathrm{wt} \%)$ at a current of $23 \mathrm{~mA}$ leads to the formation of surface layers, which abrasion resistance is 2.5-5 times higher than that of the control material. The high value of wear resistance at chromium concentration of 5 and $10 \mathrm{wt} \%$ is explained by the high content of high-strength particles (borides) in the modified layer. An increase in chromium concentration in the surfacing mixture up to 20 and $30 \mathrm{wt} \%$ leads to an increase in wear rate, since there is a decrease in the boron content in the deposited layer.

An increase in the proportion of chromium as a wetting component leads to an increase in corrosion resistance by 1.8 times. The corrosion rate for samples with $10 \mathrm{wt} \%$ chromium is $0.81 \mathrm{~mm} /$ year. With an increase to $30 \mathrm{wt} \%$, the rate decreases slightly to $1.07 \mathrm{~mm} /$ year.

The study was funded by RFBR, project number 19-33-90201. Structural research were conducted at NSTU Materials Research Center. The work is supported by Topical Plan of Novosibirsk State Technical University (NSTU), Russia, project TP-HHT-1_21.

\section{References}

1. O.I. Sleptsov, B.S. Ermakov, S.B. Ermakov, Procedia Structural Integrity 20, 130 (2019)

2. W. Mao, K. Bao, G. Liu, (...), B. Li, X. Zhao, Journal of Superhard Mate. 38, 251 (2016)

3. J.M. Costa, A.F. de Almeida Neto, Ultrason. Sonochem. 68105193 (2020)

4. L.A. Pisarevskii, G.A. Filippov, A.A. Lipatov, Metallurgist 60, 822 (2016) 
5. J.G. Checmanowski, J. Masalski, T. Oginski, Ochronaprzedkorozja 60, 222 (2017)

6. B.K. Rakhadilov, V.V. Buranich, Z.A. Satbayeva, J. Mater. Res. Technol. 9, 6969 (2020)

7. T. Xiang, J. Liu, Q. Liu, (...), D. Chen, G. Xu, Chem. Eng. J. 417 (2021)

8. F.-M. Yang, L.-X. Lian, Y. Liu, X.-F. Gong, Rare Metals 40, 2076 (2021) 